\title{
A measure of treatment response: patient and physician satisfaction with traditional NSAIDs for osteoarthritis control
}

This article was published in the following Dove Press journal:

Open Access Rheumatology: Research and Reviews

29 July 2013

Number of times this article has been viewed

\author{
Stephanie D Taylor' \\ Sharlette V Everett ${ }^{\prime}$ \\ Thomas N Taylor ${ }^{2}$ \\ Douglas J Watson ${ }^{3}$ \\ Gavin Taylor-Stokes ${ }^{4}$ \\ 'Global Health Outcomes, Merck \\ Sharp and Dohme Corp, Whitehouse \\ Station, NJ, USA; ${ }^{2}$ Pharmacy Practice, \\ Wayne State University, Detroit, MI, \\ USA; ${ }^{3}$ Epidemiology, Merck Sharp \\ and Dohme Corp, Upper Gwynedd, \\ PA, USA; ${ }^{4}$ Adelphi Real World, \\ Macclesfield, UK
}

Purpose: The clinical response to traditional nonsteroidal anti-inflammatory drugs (tNSAIDs) varies substantially. The objective of this study was to describe physicians' and patients' perceptions of response to tNSAIDs as measured by satisfaction with control of patients' osteoarthritis (OA).

Patients and methods: A cross-sectional survey was undertaken in 2009 in Germany, Spain, and the UK. Linked physician and patient questionnaires collected data on OA management, degree of pain and disability, and satisfaction with OA control.

Results: The study included 363 treating physicians and 713 patients receiving tNSAIDs. Patient mean (standard deviation) age was 65.5 (11.0) years (range 36-94 years); 60\% were women; $86 \%$ were white; and one-quarter were obese. Dissatisfaction with control of patients' OA was expressed by physicians or their patients, or both, for $51 \%$ of patients, including 208 patients (31\%) with mild OA and 478 patients (60\%) with moderate or severe OA. Overall, $37 \%$ of patients reported dissatisfaction and $34 \%$ had a physician who reported dissatisfaction. Patient and physician assessments were the same in 70\% of cases; Cohen's $\kappa$ coefficient was 0.34 (95\% confidence interval $0.26-0.41$ ), indicating fair agreement. Of those reporting dissatisfaction, most physicians $(79 \%)$ and patients (64\%) believed that the current control was the best that could be achieved. The most common reasons for which physicians reported dissatisfaction were inadequate response (56\%), side effects $(11.1 \%)$, and poor tolerance $(7.8 \%)$.

Conclusion: One-half of patients or their treating physicians were dissatisfied with the control of OA provided by tNSAID therapy; moreover, most believed it was the best control that could be achieved.

Keywords: cross-sectional, dissatisfaction, pain, survey

\section{Introduction}

Osteoarthritis (OA) is a common form of degenerative joint disease affecting an estimated 151.4 million people worldwide. ${ }^{1}$ Joint pain and stiffness, together with associated loss of function and reduced quality of life, constitute the main disease burden of OA. A worldwide public health concern, OA is one of the leading causes of long-term disability that predominantly affects people of working age and older, and is thus expected to increase in prevalence as the world's population ages. ${ }^{2,3}$ Management of OA pain is therefore an important health care goal.

There are a variety of therapies available for treating pain associated with OA. Paracetamol (or acetaminophen in the US) is recommended as the initial pharmacologic therapy for mild symptoms, followed by a traditional nonsteroidal anti-inflammatory drug (tNSAID) or cyclooxygenase-2-selective NSAID. ${ }^{2,4}$ The response to NSAIDs,
Correspondence: Stephanie D Taylor Global Health Outcomes, Merck Sharp and Dohme Corp, One Merck Drive, PO Box 100, WS2E-85, Whitehouse Station, NJ 08889, USA

$\mathrm{Tel}+\mathrm{I} 9084233512$

$\mathrm{Fax}+\mid 9087351688$

Email stephanie_taylor@merck.com 
as well as associated side effects, can vary substantially among individuals, and there is evidence that patients can be classified as responders or nonresponders to particular agents. ${ }^{5}$ The fact that therapies vary in their benefit-risk profiles, and individual patients in their responses to these therapies, reinforces the need for careful selection of therapy for each patient.

The focus of clinical trial research of OA therapies, such as NSAIDs, has typically centered on the response to treatment (relief of pain), while the consequences of inadequate pain relief are less well investigated. Moreover, the outcomes of clinical trials do not always directly translate to the real world, where patients may use their pain medication intermittently and have comorbidities that influence tolerability.

The objectives of this study were to concurrently evaluate the perceptions of physicians and patients regarding response to OA therapy in a real-world clinical care setting, as measured by satisfaction with the current control of OA among patients receiving tNSAIDs. Exploration of patient and physician satisfaction with tNSAIDs may offer information relevant for individualized management of OA.

\section{Methods}

This analysis drew on data from the 2009 Adelphi Real World Arthritis Disease Specific Program (DSP). The DSPs, described in detail elsewhere, ${ }^{6}$ are multinational crosssectional surveys of physicians and patients, conducted every 1-2 years to understand current clinical practice for common chronic diseases. The physicians who participated in the 2009 arthritis DSP were recruited by telephone from public lists of health care professionals, and included primary care physicians, rheumatologists, and orthopedists. To be eligible, physicians had to have been qualified as a physician from 1971-2007, to see a minimum of ten patients with OA per month, and to be personally involved in the drug management for arthritis. Participating physicians were asked to identify, and complete a written survey for, consecutive patients with rheumatoid arthritis or OA at any site; these patients, in turn, were asked to participate by completing a written patient survey. Physicians did not see or influence patient responses, and patient survey completion was voluntary.

The DSP was conducted under the European Pharmaceutical Market Research Association (EphMRA) code of conduct, thus ensuring compliance with Health Insurance Portability and Accountability Act (HIPAA) and all European data protection requirements. Patients were asked to provide consent before participating. Physicians were compensated for their participation in the study according to accepted research rates.

Patients with OA in Germany, Spain, and the UK who reported using a tNSAID were included in the study. Patients using disease-modifying agents and biologics were excluded. The diagnosis and severity of OA were established by the treating physicians; specification of the diagnostic test(s) leading to the OA diagnosis and severity assessment were not required.

Patients and their physicians completed standardized questionnaires to collect data on OA management, including clinical characteristics, prescribing behaviors, treatment patterns, patient-reported outcomes, and health-related quality of life. For each patient, physicians were asked, "Which of the following best describes your satisfaction with the current control of this patient's arthritis?" Each patient was asked, "Overall, are you satisfied with the current control of your arthritis medicine?" The level of satisfaction with OA control was reported by both physicians and patients as (1) satisfied; (2) not satisfied, but I believe this is the best that can be achieved; or (3) not satisfied, and I believe better control can be achieved. The meaning of the word "control" was not specified in the questionnaire and therefore was based on the physicians' and patients' subjective perception. The satisfaction question permitted each physician and patient to interpret the word "control" according to their priorities. Other patient-reported outcomes included a generic health-related quality of life instrument, the EuroQol EQ-5D; ${ }^{7}$ the Health Assessment Questionnaire (HAQ) ${ }^{8}$ and the Western Ontario and McMaster Universities OA Index (Likert scale). ${ }^{9}$

Study questionnaires were developed in English and then translated into the language of the study country by a local DSP fieldwork agency. A second independent translation agency linguistically validated each translated document. All responses were deidentified and anonymized to preserve patient confidentiality and to avoid bias at the data collection and analysis phases.

\section{Statistical analyses}

Descriptive statistics were used to describe the sample of patients using tNSAIDs. Categorical and continuous variables were compared using the Chi-squared test and $t$-test, respectively. Cohen's $\kappa$ coefficient with $95 \%$ confidence interval was derived to determine agreement between patient and physician in satisfaction with current control of OA. Analyses were carried out using Stata version 10.1 (Stata Corp LP, College Station, TX, USA) and SAS software version 9.2 (SAS Institute Inc, Cary, NC, USA). 


\section{Results}

A total of 361 physicians participated in the study, including primary care physicians (34\%), rheumatologists (54\%), and orthopedists $(12 \%)$. They completed study questionnaires for 1572 patients, of whom 1119 (71.2\%) completed the corresponding patient questionnaire. Among the patients completing the patient questionnaire, $713(63.7 \%)$ were treated with a tNSAID and were included in the analyses described here. Results by country are reported in Tables S1-S3.

Patient demographic and clinical characteristics are summarized in Table 1 for the $705 / 713$ patients with recorded OA severity, graded by physicians as mild $(\mathrm{n}=214,30 \%)$ versus moderate $(\mathrm{n}=389,55 \%)$ or severe $(\mathrm{n}=102,14 \%)$. Patients ranged in age from 36-94 years, with a mean (standard deviation) age of 65.5 (11.0) years; $60 \%$ were women; $86 \%$ were white; and the mean (standard deviation) body mass index was 27.7 (4.7). The time since the diagnosis of OA ranged from 0-27 years, with a median of 3.5 years. Patients with mild as compared with moderate or severe OA were younger, more likely to be employed, and less likely to be obese or to have a concomitant gastric condition or history of cardiovascular disease; moreover, they had less need for analgesia and were less disabled (by HAQ score) (Table 1).

Table I Characteristics of the study patient population, overall and by severity of osteoarthritis ${ }^{\mathrm{a}}$

\begin{tabular}{|c|c|c|c|c|c|c|c|}
\hline \multirow[t]{2}{*}{ Characteristic $^{\mathrm{a}}$} & \multicolumn{2}{|l|}{$\begin{array}{l}\text { Total } \\
(n=705)\end{array}$} & \multicolumn{2}{|c|}{$\begin{array}{l}\text { Mild OA } \\
(n=2 \mid 4)\end{array}$} & \multicolumn{2}{|c|}{$\begin{array}{l}\text { Moderate/severe } \mathrm{OA}^{\mathrm{b}} \\
(\mathrm{n}=49 \mathrm{I})\end{array}$} & \multirow[t]{2}{*}{$P$} \\
\hline & $\mathbf{n}$ & & $\mathbf{n}$ & & $\mathbf{n}$ & & \\
\hline Age, mean (SD) & 705 & $65.5(11.0)$ & 214 & $62.1(11.0)$ & 491 & $66.9(10.8)$ & $<0.001$ \\
\hline $36-55$ years & & 146 (20.7) & & $65(30.4)$ & & $81(16.5)$ & $<0.001$ \\
\hline $56-75$ years & & 421 (59.7) & & 123 (57.5) & & $298(60.7)$ & \\
\hline $76-85$ years & & $122(17.3)$ & & $22(10.3)$ & & $100(20.4)$ & \\
\hline$>85$ years & & $16(2.3)$ & & $4(1.9)$ & & $12(2.4)$ & \\
\hline Sex, female & 705 & $420(59.6)$ & 214 & $129(60.3)$ & 491 & 291 (59.3) & NS \\
\hline Race, white & 705 & $605(85.8)$ & 214 & I 77 (82.7) & 491 & $428(87.2)$ & NS \\
\hline Spanish/Hispanic & & $64(9.1)$ & & $21(9.8)$ & & $43(8.8)$ & \\
\hline Other & & $34(4.8)$ & & $15(7.0)$ & & $19(3.9)$ & \\
\hline Employed & 705 & $170(24.1)$ & 214 & $65(30.4)$ & 491 & $105(21.4)$ & 0.012 \\
\hline Smoker & 705 & $164(23.3)$ & 214 & $56(26.2)$ & 491 & $108(22.0)$ & NS \\
\hline BMI, mean (SD) & 705 & $27.7(4.7)$ & 214 & $26.8(4.0)$ & 491 & $28.1(4.9)$ & $<0.001$ \\
\hline Obese $\left(\mathrm{BMI} \geq 30 \mathrm{~kg} / \mathrm{m}^{2}\right)$ & 705 & $169(24.0)$ & 214 & $38(17.8)$ & 491 & $13 \mid(26.7)$ & 0.024 \\
\hline \multicolumn{8}{|l|}{ Concomitant condition } \\
\hline Gl condition & 705 & $170(24.1)$ & 214 & $32(15.0)$ & 491 & $138(28.1)$ & $<0.001$ \\
\hline History of CV disease & 705 & $403(57.2)$ & 214 & $100(46.7)$ & 491 & $303(6 I .7)$ & $<0.001$ \\
\hline Hypertension & $4 I I$ & $332(80.8)$ & 102 & $78(76.5)$ & 309 & $254(82.2)$ & NS \\
\hline Depression/anxiety & 277 & $75(27.1)$ & 64 & $19(29.7)$ & 213 & $56(26.3)$ & NS \\
\hline Other medication & 705 & & 214 & & 491 & & \\
\hline Gastroprotective agent & & $330(46.8)$ & & $75(35.1)$ & & 255 (5I.9) & $<0.00$ I \\
\hline Cardiovascular agent & & $371(52.6)$ & & $92(43.0)$ & & $279(56.8)$ & $<0.001$ \\
\hline Lipid-lowering agent & & $94(13.3)$ & & $14(6.5)$ & & $80(16.3)$ & $<0.00$ I \\
\hline \multicolumn{8}{|l|}{ Current need for analgesia ${ }^{b}$} \\
\hline $0-2.9$ (none) & 705 & $172(24.4)$ & 214 & $93(43.5)$ & 491 & $79(16.1)$ & $<0.00$ I \\
\hline $3-3.9$ & & 107 (I5.2) & & $44(20.6)$ & & $63(12.8)$ & \\
\hline $4-5.9$ & & $190(27.0)$ & & $42(19.6)$ & & $148(30.1)$ & \\
\hline $6-7.9$ & & $160(22.7)$ & & $20(9.4)$ & & | 40 (28.5) & \\
\hline 8-10 (strongest need) & & $28(4.0)$ & & $0(0.0)$ & & $28(5.7)$ & \\
\hline Osteoarthritis, knee & 705 & $467(66.2)$ & 214 & 124 (57.9) & 491 & 343 (69.9) & 0.002 \\
\hline Osteoarthritis, hip & 705 & $310(44.0)$ & 214 & 64 (29.9) & 491 & $246(50.1)$ & $\mathrm{n} / \mathrm{a}$ \\
\hline $\mathrm{HAQ}^{\mathrm{c}}$ & 683 & & 205 & & 470 & & \\
\hline $0.0-0.9$ & & $245(36.0)$ & & $124(60.5)$ & & $119(25.3)$ & $<0.001$ \\
\hline $1.0-1.9$ & & $322(47.1)$ & & $67(32.7)$ & & $250(53.2)$ & \\
\hline $2.0-2.9$ & & $114(16.7)$ & & $14(6.8)$ & & 99 (2I.I) & \\
\hline 3.0 & & $2(0.29)$ & & $0(0.0)$ & & $2(0.43)$ & \\
\hline
\end{tabular}

Notes: $P$-value calculated using the Chi-squared test for categorical values and $t$-test for continuous variables; ${ }^{a}$ values are number (\%) of patients (eight patients were missing data on OA severity); ${ }^{b}$ physician assessment; ' patient self-assessment.

Abbreviations: BMI, body mass index; CV, cardiovascular condition; GI, gastrointestinal; HAQ, Health Assessment Questionnaire (scale: zero [no disability] to three [complete disability]); n/a, not assessed; NS, not statistically significant; SD, standard deviation; OA, osteoarthritis. 
All patients were taking a tNSAID, most commonly diclofenac $(46 \%)$, ibuprofen $(37 \%)$, or naproxen $(6 \%)$. Sixty percent of patients reported good compliance (ie, "I follow the instruction fully and give my medication every chance to work"), including $63 \%$ with mild OA and 59\% with moderate to severe OA (Table 2).

Results of patient-reported measures, while variable, indicated persistent arthritis-associated disability for many patients. The mean (standard deviation) score on the generic EQ-5D was $0.59(0.28)$ on a scale of zero (dead) to one (perfect health), while mean (standard deviation) score for patient functioning on the HAQ was 1.32 (0.68) on a scale of zero (no disability) to three (complete disability). On the Western Ontario and McMaster Universities OA Index (score of zero representing best response), the average score for pain was 5.7 on a zero to 20 scale and 2.5 for stiffness on a zero to eight scale; the average score for physical functioning had a mean score of 16.1 on a zero to 68 scale.

Physicians recorded dissatisfaction with the current control of arthritis for one-third of patients ( $n=243,34 \%$; Table 3). Inadequate response was the most common reason cited for dissatisfaction, while for most of these patients, the prescribing physician believed that the current state of control was the best that could be achieved (Table 3). The replies of patients regarding satisfaction with their arthritis medication were proportionately similar to those of physicians $(37 \%$ dissatisfied). Patient and physician assessments were the same in $70 \%$ of cases; the $\kappa$ coefficient was $0.34(95 \%$ confidence interval $0.26-0.41)$, indicating fair agreement. Overall, for 351/688 (51\%) of patients, either the physician or the patient, or both, were dissatisfied. Only one-third of dissatisfied patients believed that better control of their arthritis could be achieved (Table 3).
Dissatisfaction with OA control was significantly more frequent for patients with moderate or severe OA than for those with mild OA (Table 3). Physicians recorded dissatisfaction with arthritis control for $14 \%$ of patients with mild and $43 \%$ of those with moderate to severe OA; the causes of dissatisfaction were similar among physicians regardless of OA severity. Among patients themselves, dissatisfaction was expressed by $24 \%$ of those with mild and $43 \%$ of those with moderate or severe OA. Patient and physician assessments were more often the same for patients with mild OA ( $76 \%$ versus $66 \%$ of those with moderate or severe disease). For $31 \%$ of patients with mild and $60 \%$ of those with moderate or severe OA, either the physician or the patient, or both, were dissatisfied.

\section{Discussion}

This study provides comprehensive data from both physicians and consulting patients in three European countries on physician prescribing behaviors and satisfaction with control of OA provided by tNSAID treatment. It was found that for one-half of patients, either the physician, patient, or both were dissatisfied with OA control provided by tNSAIDs. Not surprisingly, this figure was higher for those patients with moderate or severe OA $(60 \%)$ than for those with mild disease (31\%). Thus, despite multiple options for tNSAID therapy, there is still an unmet medical need for alternative treatment options for patients and physicians to adequately treat OA.

The majority of physicians and patients who reported dissatisfaction in this survey also reported that they believed that the current level of OA control was the best that could be achieved for the patient. Interestingly, fewer physicians (21\%) than patients $(36 \%)$ believed that better control could be achieved. Given the importance of the patient-physician

Table 2 Self-reported patient compliance for prescribed osteoarthritis medications, overall and by severity of osteoarthritis ${ }^{\mathrm{a}}$

\begin{tabular}{|c|c|c|c|}
\hline Characteristic & $\begin{array}{l}\text { Total } \\
(n=7 \mid 3)\end{array}$ & $\begin{array}{l}\text { Mild OA } \\
(n=2 \mid 4)\end{array}$ & $\begin{array}{l}\text { Moderate/severe } \text { OA }^{\mathrm{b}} \\
(\mathrm{n}=49 \mathrm{I})\end{array}$ \\
\hline I follow the instruction fully and give my medication every chance to work & $429(60.2)$ & $135(63.1)$ & $288(58.7)$ \\
\hline $\begin{array}{l}\text { I follow the instructions fully but sometimes forget to take the medication } \\
\text { on the right day }\end{array}$ & $154(21.6)$ & $43(20.1)$ & $110(22.4)$ \\
\hline $\begin{array}{l}\text { I follow the instructions fully but am quick to give up if it doesn't work } \\
\text { straight away or I get side effects }\end{array}$ & $53(7.4)$ & $13(6.1)$ & $40(8.2)$ \\
\hline $\begin{array}{l}\text { It varies, I tend to take my medication for a while and then stop and/or take } \\
\text { it when I remember }\end{array}$ & $26(3.7)$ & $5(2.3)$ & $20(4.1)$ \\
\hline It varies, I tend to take my medication only when symptoms occur or worsen & $54(7.6)$ & $21(9.8)$ & $33(6.7)$ \\
\hline $\begin{array}{l}\text { It varies, I tend to take my medication only when I know I may get a flare } \\
\text { up/worsening of my arthritis }\end{array}$ & $14(2.0)$ & $4(1.9)$ & $10(2.0)$ \\
\hline
\end{tabular}

Notes: There were no statistically significant differences between patients with mild versus moderate/severe OA (Chi-squared test); avalues are number (\%) of patients (eight patients were missing data on OA severity); ${ }^{\text {p}}$ hysicians graded severity of $\mathrm{OA}$ as mild, moderate, or severe. Abbreviation: $\mathrm{OA}$, osteoarthritis. 
Table 3 Physician and patient satisfaction with treatments prescribed ${ }^{a}$

\begin{tabular}{|c|c|c|c|c|}
\hline & $\begin{array}{l}\text { Total } \\
(n=7 \mid 3)\end{array}$ & $\begin{array}{l}\text { Mild OA } \\
(n=2 \mid 4)\end{array}$ & $\begin{array}{l}\text { Moderate/severe } O^{b} \\
(n=49 I)\end{array}$ & $\mathbf{P}$ \\
\hline Physicians' responses & $(n=709)$ & $(n=213)$ & $(n=488)$ & \\
\hline Satisfied & $466(65.7)$ & $183(85.9)$ & $278(57.0)$ & $<0.001$ \\
\hline Dissatisfied & $243(34.3)$ & $30(14.1)$ & $210(43.0)$ & \\
\hline Believe this is the best that can be achieved for this patient & $191(78.6)$ & $22(73.3)$ & $167(79.5)$ & \\
\hline Believe better control can be achieved for this patient & $52(21.4)$ & $8(26.7)$ & $43(20.5)$ & \\
\hline Causes of dissatisfaction & $(n=243)$ & $(n=30)$ & $(n=210)$ & \\
\hline Inadequate response & $135(55.6)$ & $16(53.3)$ & $116(55.2)$ & NS \\
\hline Side effects & $27(11.1)$ & $3(10.0)$ & $24(11.4)$ & NS \\
\hline Poor tolerance & $19(7.8)$ & $2(6.7)$ & $16(7.6)$ & NS \\
\hline Other & $58(23.5)$ & $8(26.7)$ & $49(23.3)$ & NS \\
\hline Not stated & $22(9.1)$ & I (3.3) & $21(10)$ & NS \\
\hline Patients' responses & $(n=692)$ & $(\mathrm{n}=208)$ & $(n=478)$ & \\
\hline Satisfied & $433(62.6)$ & $158(76.0)$ & $273(57.1)$ & $<0.001$ \\
\hline Dissatisfied & $259(37.4)$ & $50(24.0)$ & $205(42.9)$ & \\
\hline Believe this is best that can be achieved for my arthritis & $157(64.1)$ & $31(66.0)$ & $125(64.1)$ & $<0.001$ \\
\hline Believe better control can be achieved for my arthritis & $88(35.9)$ & $16(34.0)$ & $70(35.9)$ & \\
\hline Physicians' and patients' responses ${ }^{c}$ & $(n=688)$ & $(n=207)$ & $(n=475)$ & \\
\hline In agreement & $478(69.1)$ & $158(76.3)$ & $315(66.3)$ & $<0.001$ \\
\hline Both satisfied & $337(70.5)$ & $143(69.1)$ & $192(40.4)$ & \\
\hline Both dissatisfied & |4| (29.5) & $15(7.3)$ & $123(25.9)$ & \\
\hline Not in agreement & $210(30.3)$ & $49(23.7)$ & $160(33.7)$ & \\
\hline Physician satisfied, patient dissatisfied & $117(55.7)$ & $34(16.4)$ & $82(17.3)$ & \\
\hline Physician dissatisfied, patient satisfied & $93(44.3)$ & $15(7.3)$ & $78(16.4)$ & \\
\hline
\end{tabular}

Notes: $P$-value comparing mild versus moderate/severe (Chi-squared test); ${ }^{2}$ values are number (\%) of patients (eight patients were missing data on OA severity); ${ }^{\mathrm{b}}$ physicians graded severity of $O A$ as mild, moderate, or severe (severity grade responses missing for eight patients); 'Cohen's $\kappa$ coefficient $=0.34$ ( $95 \%$ confidence interval $0.26-0.41$ ). Abbreviations: OA, osteoarthritis; NS, not statistically significant.

relationship, further research should explore the apparent disconnect suggested by the $\kappa$ coefficient of 0.34 , indicating only fair agreement between patient and physician assessments regarding satisfaction with current control of OA.

Satisfaction with control of OA was measured as a proxy for physicians' and patients' assessments about the effectiveness of therapy; conversely, dissatisfaction with control of OA served as a proxy for inadequate response. In a prior study, Dworkin et al used a patient-completed global assessment of treatment satisfaction to assess response to therapy with a lidocaine patch for knee OA and chronic low back pain. ${ }^{10}$ They found that improvements in measures of pain intensity, pain relief, and interference with physical functioning each made independent contributions to treatment satisfaction, whereas adverse events and improvements in emotional functioning and sleep did not. Results of other studies indicate that measures of treatment satisfaction improve concurrently with improvements in pain, function, and quality of life. ${ }^{11,12}$

Possible reasons for dissatisfaction were evaluated and it was found that inadequate response to treatment was the most common reason reported by physicians. Dissatisfaction with treatment can, in turn, lead to noncompliance, increased health care resource use such as repeat clinical visits, and switching to other therapies for pain. Indeed, switching is common for patients receiving tNSAIDs. ${ }^{13,14}$

The strengths of this study are the inclusion of large numbers of physicians and their patients as part of a wellestablished survey, the inclusion of different types of health care providers, a real-world population that included some patients who might not be eligible for randomized clinical trials of treatment efficacy, and the concurrent assessment of physicians and patients for their satisfaction with control of arthritis. Similar to findings in other studies, it was found that patient and physician assessments may differ; this is true for global assessments in rheumatoid arthritis. ${ }^{15}$

Limitations of this purely descriptive study include the potential for recall bias, misunderstanding of survey questions, and other common limitations associated with use of survey instruments, including the potential for selection bias leading to lack of generalizability because only those patients who agreed to complete the questionnaires were included. The results may not represent all regions or practices in the selected countries. Some data were missing, including OA severity for eight patients and some patient self-assessment data, including HAQ data for 30/713 (4\%) patients; 21/713 (3\%) patients did not reply to the satisfaction question, with 
matched physician-patient responses to the satisfaction question missing for 25/713 (4\%) of patients. Moreover, it was not assessed which joints were affected by OA nor the effect of nonpharmacologic modalities of pain relief used in conjunction with tNSAIDs. Finally, patients with moderate and severe OA were grouped together because of the small numbers with severe OA.

\section{Conclusion}

This study found there was dissatisfaction with the control of arthritis for $51 \%$ of patients receiving current tNSAID therapy, including $60 \%$ of those with moderate or severe OA, as expressed by physicians or patients or both. Dissatisfaction was largely related to treatment effectiveness (inadequate response); issues of tolerability were less commonly linked to dissatisfaction by physicians. Further research is needed to explore inadequate control of OA by tNSAIDs. In particular, the associations between inadequate control and outcomes such as uncontrolled pain, repeat physician visits, health care resource use, noncompliance, and switching to other therapies warrant further investigation.

\section{Acknowledgments}

These analyses were funded by Merck Sharp and Dohme Corp, (Whitehouse Station, NJ, USA); the DSP survey was funded by Merck Sharp and Dohme Corp, together with other pharmaceutical companies.

\section{Disclosure}

SD Taylor, SV Everett, and DJ Watson are employees of Merck Sharp and Dohme Corp, a subsidiary of Merck and Co, Inc (Whitehouse Station, NJ, USA); TN Taylor has no conflicts of interest to declare; G Taylor-Stokes is an employee of Adelphi Real World. Medical writing and editorial assistance was provided by Elizabeth V Hillyer, which was funded by Merck Sharp and Dohme Corp.

\section{References}

1. World Health Organization. The Global Burden of Disease: 2004 Update. Geneva: World Health Organization; 2008. Available from: http://www. who.int/healthinfo/global_burden_disease/GBD_report_2004update_ full.pdf. Accessed March 27, 2013.
2. National Institute for Health and Clinical Excellence. CG59 Osteoarthritis: The Care and Management of Osteoarthritis in Adults. London: Royal College of Physicians; 2008. Available from: http:// www.nice.org.uk/nicemedia/live/11926/39720/39720.pdf. Accessed December 10, 2012.

3. Woolf AD, Pfleger B. Burden of major musculoskeletal conditions. Bull World Health Organ. 2003;81(9):646-656.

4. Zhang W, Nuki G, Moskowitz RW, et al. OARSI recommendations for the management of hip and knee osteoarthritis: part III: changes in evidence following systematic cumulative update of research published through January 2009. Osteoarthritis Cartilage. 2010;18(4):476-499.

5. Walker JS, Sheather-Reid RB, Carmody JJ, Vial JH, Day RO. Nonsteroidal antiinflammatory drugs in rheumatoid arthritis and osteoarthritis: support for the concept of "responders" and "nonresponders." Arthritis Rheum. 1997;40(11):1944-1954.

6. Anderson P, Benford M, Harris N, Karavali M, Piercy J. Realworld physician and patient behaviour across countries: DiseaseSpecific Programmes - a means to understand. Curr Med Res Opin. 2008;24(11):3063-3072.

7. EQ-5D [homepage on the Internet]. Rotterdam: EuroQol Group; 2002 [updated March 1, 2013]. Available from: http://www.euroqol.org/. Accessed December 10, 2012.

8. Fries JF, Spitz P, Kraines RG, Holman HR. Measurement of patient outcome in arthritis. Arthritis Rheum. 1980;23(2):137-145.

9. Bellamy N, Buchanan WW, Goldsmith CH, Campbell J, Stitt LW. Validation study of WOMAC: a health status instrument for measuring clinically important patient relevant outcomes to antirheumatic drug therapy in patients with osteoarthritis of the hip or knee. J Rheumatol. 1988;15(12):1833-1840.

10. Dworkin RH, Jensen MP, Gould E, et al. Treatment satisfaction in osteoarthritis and chronic low back pain: the role of pain, physical and emotional functioning, sleep, and adverse events. J Pain. 2011;12(4): 416-424.

11. Lin HY, Cheng TT, Wang JH, et al. Etoricoxib improves pain, function and quality of life: results of a real-world effectiveness trial. Int J Rheum Dis. 2010;13(2):144-150.

12. Ramos-Remus CR, Hunsche E, Mavros P, Querol J, Suarez R. Evaluation of quality of life following treatment with etoricoxib in patients with arthritis or low-back pain: an open label, uncontrolled pilot study in Mexico. Curr Med Res Opin. 2004;20(5):691-698.

13. Langman M, Kahler KH, Kong SX, et al. Drug switching patterns among patients taking non-steroidal anti-inflammatory drugs: a retrospective cohort study of a general practitioners database in the United Kingdom. Pharmacoepidemiol Drug Saf. 2001;10(6):517-524.

14. Rahme E, Toubouti Y, Hunsche E. Therapy switching and associated costs in elderly patients receiving COX-2 selective inhibitors or nonselective non-steroidal anti-inflammatory drugs in Quebec, Canada. Rheumatology (Oxford). 2006;45(7):903-910.

15. Rohekar G, Pope J. Test-retest reliability of patient global assessment and physician global assessment in rheumatoid arthritis. $J$ Rheumatol. 2009;36(10):2178-2182. 


\section{Supplementary tables}

Table SI Characteristics of the study patient population, overall and by country

\begin{tabular}{|c|c|c|c|c|c|c|c|c|c|}
\hline \multirow[t]{2}{*}{ Characteristic $^{\mathrm{a}}$} & \multicolumn{2}{|c|}{$\begin{array}{l}\text { Total } \\
(n=7 \mid 3)\end{array}$} & \multicolumn{2}{|c|}{$\begin{array}{l}\text { Germany } \\
(n=344)\end{array}$} & \multicolumn{2}{|c|}{$\begin{array}{l}\text { Spain } \\
(n=252)\end{array}$} & \multicolumn{2}{|c|}{$\begin{array}{l}\text { UK } \\
(n=1 \mid 7)\end{array}$} & \multirow[t]{2}{*}{$P$} \\
\hline & n & & $\mathbf{n}$ & & $\mathbf{n}$ & & n & & \\
\hline Age, mean (SD) years & 713 & $65.5(11.0)$ & 344 & $64.8(11.1)$ & 252 & 66.5 (II.I) & 117 & $65.1(10.4)$ & NS \\
\hline $36-55$ years & & $146(20.5)$ & & 71 (20.6) & & $51(20.2)$ & & $24(20.5)$ & \\
\hline $56-75$ years & & $428(60.0)$ & & $212(61.6)$ & & $147(58.3)$ & & $69(59.0)$ & \\
\hline $76-85$ years & & $123(17.3)$ & & $54(I 5.7)$ & & $46(18.3)$ & & $23(19.7)$ & \\
\hline$>85$ years & & $16(2.2)$ & & $7(2.0)$ & & $8(3.2)$ & & I (0.9) & \\
\hline Sex, female & 712 & 427 (59.9) & 344 & $200(58.1)$ & 251 & $169(67.3)$ & 117 & $58(49.6)$ & 0.01 \\
\hline Race, white & 713 & 611 (85.7) & 344 & 337 (98.0) & 252 & 177 (70.2) & 117 & 97 (82.9) & $<0.001$ \\
\hline Spanish/Hispanic & & $66(9.3)$ & & $\mathrm{I}(0.3)$ & & $64(25.4)$ & & I (0.9) & \\
\hline Other & & $36(5.0)$ & & $6(1.7)$ & & II (4.4) & & $19(16.2)$ & \\
\hline Employed & 707 & $170(23.8)$ & 340 & 91 (26.8) & 251 & $48(19.1)$ & 116 & $31(26.7)$ & NS \\
\hline Smoker & 692 & $164(23.0)$ & 336 & $84(25.0)$ & 242 & $61(26.4)$ & 114 & $19(16.7)$ & NS \\
\hline BMI, mean (SD) & 701 & $27.7(4.7)$ & 343 & $28.3(5.2)$ & 249 & $27.3(3.6)$ & 109 & $26.4(4.7)$ & $<0.001$ \\
\hline Obese $(\mathrm{BMI} \geq 30)$ & & $170(24.3)$ & & 99 (28.9) & & $52(20.9)$ & & $19(17.4)$ & \\
\hline \multicolumn{10}{|l|}{ Concomitant condition } \\
\hline Gl condition & 713 & I7I (24.0) & 344 & $67(19.5)$ & 252 & $78(31.0)$ & 117 & $26(22.2)$ & 0.005 \\
\hline History of CV disease & 713 & $404(56.7)$ & 344 & $203(59.0)$ & 252 & $156(6 \mid .9)$ & 117 & $45(38.5)$ & $<0.001$ \\
\hline Hypertension & 404 & $333(82.4)$ & 203 & $173(85.2)$ & 156 & 121 (77.6) & 45 & $39(86.7)$ & NS \\
\hline Depression/anxiety & 284 & $78(27.5)$ & 122 & $25(20.5)$ & 124 & $43(34.7)$ & 38 & $10(26.3)$ & 0.04 \\
\hline Other medication & 713 & & 344 & & 252 & & 117 & & \\
\hline Gastroprotective agent & & $335(47.0)$ & & III (32.3) & & $184(73.0)$ & & $40(34.2)$ & $<0.00$ I \\
\hline Cardiovascular agent & & $375(52.6)$ & & $182(52.9)$ & & $138(54.8)$ & & $55(47.0)$ & NS \\
\hline Lipid-lowering agent & & $95(13.3)$ & & $50(14.5)$ & & $39(15.5)$ & & $6(5.1)$ & 0.02 \\
\hline OA severity, $\mathrm{b}$ mild & 705 & $214(30.0)$ & 342 & $99(28.9)$ & 247 & $77(3 \mid .2)$ & 116 & $38(32.8)$ & $<0.001$ \\
\hline Moderate & & $389(54.6)$ & & $170(49.7)$ & & 148 (59.9) & & $7 \mid(6 \mid .2)$ & \\
\hline Severe & & $102(14.3)$ & & $73(21.3)$ & & $22(8.9)$ & & $7(6.0)$ & \\
\hline \multicolumn{10}{|l|}{ Current need for analgesia ${ }^{b}$} \\
\hline Mean (SD) & 665 & $4.2(2.1)$ & 339 & $3.8(2.1)$ & 210 & $4.6(2.1)$ & 116 & $4.6(2.0)$ & $<0.001$ \\
\hline $0-2.9$ (none) & 665 & $174(24.4)$ & 339 & $112(33.0)$ & 210 & $39(18.6)$ & 116 & $23(19.8)$ & $<0.001$ \\
\hline $3-3.9$ & & $110(15.4)$ & & $62(18.3)$ & & $30(14.3)$ & & $18(15.5)$ & \\
\hline $4-5.9$ & & $190(26.7)$ & & $93(27.4)$ & & $61(29.0)$ & & $36(31.0)$ & \\
\hline $6-7.9$ & & $163(22.9)$ & & $61(18.0)$ & & 71 (33.8) & & $31(26.7)$ & \\
\hline 8-10 (strongest need) & & $28(3.9)$ & & II (3.2) & & $9(4.3)$ & & $8(6.9)$ & \\
\hline Osteoarthritis, knee & 713 & $472(66.2)$ & 344 & $226(65.7)$ & 252 & $175(69.4)$ & 117 & 71 (60.9) & NS \\
\hline EQ-5D, mean $(S D)^{c}$ & 713 & $0.59(0.28)$ & 344 & $0.61(0.27)$ & 252 & $0.55(0.30)$ & 117 & $0.61(0.28)$ & $<0.001$ \\
\hline HAQ, mean $(S D)^{c}$ & 713 & $1.32(0.68)$ & 344 & $1.26(0.68)$ & 252 & $1.37(0.63)$ & 117 & I.37 (0.77) & $<0.001$ \\
\hline $0.0-0.9$ & 713 & $245(35.9)$ & 344 & $132(39.4)$ & 252 & $69(29.1)$ & 117 & $44(39.6)$ & 0.02 \\
\hline $1.0-1.9$ & & $322(47.1)$ & & 148 (44.2) & & $132(55.7)$ & & $42(37.8)$ & \\
\hline $2.0-2.9$ & & $114(16.7)$ & & $53(15.8)$ & & $36(15.2)$ & & $25(22.5)$ & \\
\hline 3.0 & & $2(0.3)$ & & $2(0.6)$ & & $0(0.0)$ & & $0(0.0)$ & \\
\hline WOMAC, mean $(S D)^{c}$ & 519 & $29.1(17.2)$ & 241 & $29.6(16.5)$ & 190 & $27.7(16.5)$ & 88 & $30.3(19.5)$ & NS \\
\hline Pain & 552 & $5.7(3.7)$ & 263 & $5.6(3.4)$ & 196 & $5.7(3.6)$ & 93 & $5.9(20.0)$ & NS \\
\hline Stiffness & 531 & $2.5(1.7)$ & 248 & $2.4(1.7)$ & 192 & $2.6(1.6)$ & 91 & $2.8(1.7)$ & NS \\
\hline Physical function & 681 & $16.1(4.2)$ & 322 & $16.4(14.4)$ & 245 & $15.5(13.7)$ & 114 & $16.6(15.0)$ & NS \\
\hline
\end{tabular}

Notes: $P$-value calculated using the Chi-squared test for categorical values and $t$-test for continuous variables; ${ }^{a}$ values are number (\%) of patients unless otherwise indicated;

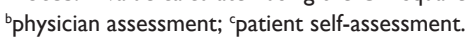

Abbreviations: BMI, body mass index; CV, cardiovascular condition; EQ-5D, EuroQol health-related quality of life (score range: zero [dead] to one [perfect health]); GI, gastrointestinal; HAQ, Health Assessment Questionnaire (scale: zero [no disability] to three [complete disability]); OA, osteoarthritis; WOMAC, Western Ontario and McMaster Universities OA Index (score range [zero is best]: pain zero to 20; stiffness zero to eight; physical function zero to 68); NS, not statistically significant. 
Table S2 Traditional nonsteroidal anti-inflammatory drug use, overall and by country ${ }^{\mathrm{a}}$

\begin{tabular}{|c|c|c|c|c|c|}
\hline Medications & $\begin{array}{l}\text { Total } \\
(n=7 \mid 3)\end{array}$ & $\begin{array}{l}\text { Germany } \\
(n=344)\end{array}$ & $\begin{array}{l}\text { Spain } \\
(n=252)\end{array}$ & $\begin{array}{l}\text { UK } \\
(n=I \mid 7)\end{array}$ & $P$ \\
\hline Diclofenac & $325(45.6)$ & $203(59.0)$ & $64(25.4)$ & $58(49.6)$ & $<0.001$ \\
\hline Ibuprofen & $262(36.8)$ & $133(38.7)$ & $97(38.5)$ & $32(27.4)$ & NS \\
\hline Naproxen & $41(5.8)$ & $2(0.6)$ & $23(9.1)$ & $16(13.7)$ & $<0.001$ \\
\hline Meloxicam & $33(4.6)$ & $4(1.2)$ & $23(9.1)$ & $6(5.1)$ & $<0.001$ \\
\hline Aceclofenac & $26(3.7)$ & $2(0.6)$ & $24(9.5)$ & $0(0.0)$ & $<0.001$ \\
\hline Ketoprofen & $16(2.2)$ & $2(0.6)$ & $14(5.6)$ & $0(0.0)$ & $<0.001$ \\
\hline Indomethacin & $12(1.7)$ & $7(2.0)$ & $5(2.0)$ & $0(0.0)$ & NS \\
\hline Piroxicam & $12(1.7)$ & $\mathrm{I}(0.3)$ & $7(2.8)$ & $4(3.4)$ & 0.02 \\
\hline Etodolac & $3(0.4)$ & $0(0.0)$ & $0(0.0)$ & $3(2.6)$ & $<0.001$ \\
\hline
\end{tabular}

Note: aPatients could be on more than one drug.

Abbreviation: NS, not statistically significant.

Table S3 Physician and patient satisfaction with treatments prescribed, overall and by country ${ }^{\mathrm{a}}$

\begin{tabular}{|c|c|c|c|c|c|}
\hline & $\begin{array}{l}\text { Total } \\
(n=7 \mid 3)\end{array}$ & $\begin{array}{l}\text { Germany } \\
(n=344)\end{array}$ & $\begin{array}{l}\text { Spain } \\
(n=252)\end{array}$ & $\begin{array}{l}\text { UK } \\
(n=117)\end{array}$ & $\mathbf{P}$ \\
\hline Physicians' responses & $(n=709)$ & $(n=342)$ & $(n=25 I)$ & $(n=116)$ & \\
\hline Satisfied & $466(65.7)$ & $234(68.4)$ & $153(60.7)$ & $79(67.5)$ & NS \\
\hline Dissatisfied & $243(34.3)$ & $108(31.6)$ & $98(39.0)$ & $37(31.9)$ & \\
\hline Believe this is the best that can be achieved for this patient & $191(78.6)$ & $77(7 I .3)$ & $82(83.7)$ & $32(86.5)$ & \\
\hline Believe better control can be achieved for this patient & $52(21.4)$ & $31(28.7)$ & $16(16.3)$ & $5(13.5)$ & \\
\hline Causes of dissatisfaction & $(n=243)$ & $(n=108)$ & $(n=98)$ & $(\mathrm{n}=37)$ & \\
\hline Inadequate response & $135(55.6)$ & $50(46.3)$ & $63(64.3)$ & $22(59.5)$ & 0.03 \\
\hline Side effects & $27(11.1)$ & $10(9.3)$ & $9(9.2)$ & $8(21.6)$ & NS \\
\hline Poor tolerance & $19(7.8)$ & $5(4.6)$ & II (II.2) & $3(8.1)$ & NS \\
\hline Other & $58(23.5)$ & $39(36.1)$ & $15(15.3)$ & $4(8.1)$ & $<0.001$ \\
\hline Not stated & $22(9.1)$ & $7(6.5)$ & $10(10.2)$ & $5(13.5)$ & NS \\
\hline Patients' responses & $(n=692)$ & $(n=338)$ & $(n=242)$ & $(n=112)$ & \\
\hline Satisfied & $433(62.6)$ & $225(66.6)$ & $137(56.6)$ & $71(63.4)$ & 0.05 \\
\hline Dissatisfied & $259(37.4)$ & $113(33.4)$ & $105(43.4)$ & $41(36.6)$ & \\
\hline Believe this is best that can be achieved for my arthritis & $157(64.1)$ & $72(63.7)$ & $60(57.1)$ & $25(61.0)$ & NS \\
\hline Believe better control can be achieved for my arthritis & $88(35.9)$ & 37 (32.7) & $35(33.3)$ & $16(39.0)$ & \\
\hline Physicians' and patients' responses & $(n=688)$ & $(n=336)$ & $(n=24 I)$ & $(n=I I I)$ & \\
\hline Concordant & $478(69.1)$ & $242(71.6)$ & $156(64.5)$ & $80(7 \mathrm{I} .4)$ & \\
\hline Both satisfied & $337(70.5)$ & $180(74.4)$ & $98(62.8)$ & $59(73.8)$ & \\
\hline Both dissatisfied & $|4|(29.5)$ & $62(25.6)$ & $58(37.2)$ & $21(26.3)$ & \\
\hline Discordant & $210(30.3)$ & $94(27.8)$ & $85(35.1)$ & $31(27.7)$ & \\
\hline Physician satisfied, patient dissatisfied & $117(55.7)$ & $50(53.2)$ & $47(55.3)$ & $20(64.5)$ & \\
\hline Physician dissatisfied, patient satisfied & $93(44.3)$ & $44(46.8)$ & $38(44.7)$ & II (35.5) & \\
\hline
\end{tabular}

Note: ${ }^{2}$ alues are $n(\%)$.

Abbreviation: NS, not statistically significant.

\section{Publish your work in this journal}

Open Access Rheumatology Research and Reviews is an international, peer-reviewed, open access journal, publishing all aspects of clinical and experimental rheumatology in the clinic and laboratory including the following topics: Pathology, pathophysiology of rheumatological diseases; Investigation, treatment and management of rheumatological diseases; Clinical trials and novel pharmacological approaches for the treatment of rheumatological disorders. The manuscript management system is completely online and includes a very quick and fair peerreview system, which is all easy to use. Visit http://www.dovepress.com/ testimonials.php to read real quotes from published authors. 